\title{
Sociodemographic Factors and Comorbidities Associated with Remission from Alcohol Dependence: Results from a Nationwide General Population Survey in Korea
}

\author{
Song Yi Han', Maeng Je Cho², Seunghee Won ${ }^{1}$, Jin Pyo Hong ${ }^{3}$, Jae Nam Bae ${ }^{4}$, Seong-Jin Cho ${ }^{5}$, \\ Jong-lk Park ${ }^{6}$, Jun-Young Lee ${ }^{7}$, Hong Jin Jeon ${ }^{3}$, and Sung Man Chang ${ }^{1 凶}$ \\ ${ }^{1}$ Department of Psychiatry, Kyungpook National University School of Medicine, Daegu, Republic of Korea \\ 2Department of Psychiatry, Seoul National University College of Medicine, Seoul National University Hospital, Seoul, Republic of Korea \\ ${ }^{3}$ Department of Psychiatry, Samsung Medical Center, Sungkyunkwan University School of Medicine, Seoul, Republic of Korea \\ ${ }^{4}$ Department of Psychiatry, College of Medicine, Inha University, Incheon, Republic of Korea \\ ${ }^{5}$ Department of Psychiatry, Gachon University of Medicine and Science, Incheon, Republic of Korea \\ ${ }^{6}$ Department of Psychiatry, Kangwon National University College of Medicine, Chuncheon, Republic of Korea \\ ${ }^{7}$ Department of Psychiatry, Seoul National University Boramae Hospital, Seoul, Republic of Korea
}

Objective The lifetime prevalence of alcohol dependence in South Korea remains higher than other countries. The aim of our study is to identify factors associated with remission from alcohol dependence.

Methods Data from the Korean Epidemiological Catchment Area-Replication (KECA-R) study were used in our study. The Korean version of the Composite International Diagnostic Interview 2.1 (K-CIDI 2.1) was administered. Remission was defined as having no symptom of alcohol dependence for 12 months or longer at the time of the interview. Demographic and clinical variables putatively associated with remission from alcohol dependence were examined by t-test, chi-square-test and logistic regression analysis.

Results The lifetime prevalence rate of alcohol dependence was $7.0 \%$. Among them, $3.2 \%$ of the subjects were diagnosed with active alcohol dependence in the previous 12 months, and 3.8\% were found to be in remission. Subjects in 35- to 44-year-old group, not living with partner group, and lower level of educational attainment group were more likely to be in the active alcohol dependence state. Of the comorbid mental disorders, dysthymia, anxiety disorder, nicotine use, and nicotine dependence were more common among the actively alcohol-dependent subjects.

Conclusion There is considerable level of recovery from alcohol dependence. Attention to factors associated with remission from alcohol dependence may be important in designing more effective treatment and prevention programs in this high-risk population.

Psychiatry Investig 2015;12(3):316-323

Key Words Alcohol, Dependence, Remission.

\section{INTRODUCTION}

Alcohol dependence is a condition characterized by a maladaptive pattern of alcohol consumption that leads to significant distress or impairments in social, occupational, or interpersonal activities. It is a major source of comorbidity in

Received: July 14, 2014 Revised: September 24, 2014

Accepted: September 30, 2014 Available online: July 6, 2015

$\triangle$ Correspondence: Sung Man Chang, MD, PhD

Department of Psychiatry, Kyungpook National University School of Medicine, 130 Dongdeok-ro, Jung-gu, Daegu 700-721, Republic of Korea Tel: +82-53-420-5753, Fax: +82-53-426-5361, E-mail: psyjang@knu.ac.kr

(a) This is an Open Access article distributed under the terms of the Creative Commons Attribution Non-Commercial License (http://creativecommons.org/licenses/bync/3.0) which permits unrestricted non-commercial use, distribution, and reproduction in any medium, provided the original work is properly cited. association with affective, anxiety, and personality disorders. ${ }^{1,2}$ In 1984, the lifetime prevalence of alcohol use disorder (AUD) in South Korea was 23\%; a rate exceeding those of other countries. ${ }^{3}$ A decline was reported by a recent national epidemiological survey conducted in 2006, however, showing $16.2 \%$, reflecting critical socio-cultural changes. During the last 20 years, Korea has experienced dramatic socio-cultural changes where life-styles and thinking patterns have become rather individualistic. The tradition of forceful heavy drinking has been disappearing, and indiscrete heavy drinking and the associated problems have become less socially acceptable. ${ }^{3}$ However, the lifetime prevalence of AUD is still higher than in other Asian countries (lifetime prevalence of AUD in China: 5.7\%, one-year prevalence of AUD in Japan: $1.7 \%) .{ }^{4}$ In addi- 
tion, alcohol dependence and other alcohol-use disorders contribute to the development of more than 60 disease conditions and account for $4 \%$ of the global burden of disease. ${ }^{5}$

The DSM-IV (American Psychiatric Association, 1995) defines remission from alcohol dependence as when none of the criteria for alcohol dependence or abuse have been met during a period of 12 months or longer. According to several Western studies, the female gender, older age at assessment, being married, more robust social support, younger age at the onset of alcohol dependence, less quantity of drinking, and less severity of drinking all tend to be positively associated with remission..$^{6-8}$ Although research has delineated factors that pose increased risk for alcohol dependence, little is known about factors associated with remission from alcohol dependence in South Korea.

Alcohol dependence tends to co-occur with other psychiatric disorders much more frequently than would be expected by chance. ${ }^{9}$ A number of studies have indicated that patients with co-existing psychiatric and alcohol use disorders have worse prognoses than those with no psychopathology, including a decreased rate of remission and increased vulnerability for relapse. ${ }^{10}$ For example, the prevalence of an alcohol disorder among individuals with depression was higher than in the general population and the odds of alcohol dependence were greater among those with major depression relative to those without it. ${ }^{11}$ According to a recent 120-day follow-up study, patients with a baseline anxiety disorder were significantly more likely than others to meet various definitions of drinking relapse over the course of the follow-up. ${ }^{12}$ In particular, social anxiety disorder was reported to be associated with significantly increased rates of alcohol dependence in both clinical studies and those conducted in the general population. ${ }^{13}$

Despite the high prevalence of alcohol use disorders in South Korea, factors associated with remission from alcohol dependence have not been examined. In 2006, the Korean Epidemiological Catchment Area (KECA-R) study, a nationwide survey of a representative sample of Korean adults aged 18-64 years, was conducted to investigate the lifetime risk of mental disorders in the general Korean population. In order to gain insight into possible factors influencing risk, severity, and recovery in alcohol dependence, differences in socio-demographic characteristics and psychiatric comorbidities between active and remitted alcohol dependence cases were examined. The aim of the present study is to identify factors associated with remission from alcohol dependence.

\section{METHODS}

\section{Sample}

Data from the KECA-R study, conducted from July 2006 to April 2007, were used in our study. The KECA-R study was carried out to estimate the prevalence and correlates of psychiatric disorders in Korean adults, which was conducted based on Korean Mental Health Act.

The 2005 Population Census Data at the Korea National Statistical Office was used to create the sampling frames. Twelve catchment areas were selected from a list of all catchment areas in 6 administrative divisions of Korea-Seoul Special city, Gyeonggi-do/Incheon Metropolitan city, Chungcheong-do, Jeolla-do, Gangwon-do, and Gyeongsang-do. A total of 7,968 households in 239 clusters were selected from the 12 catchment areas, using probability proportional to size estimated jointly by the Korean Statistical Association and the Korea National Statistical Office. One individual per selected household was randomly chosen; this was the individual with the earliest birthday without consideration of month or year. From an initially selected 7,968 subjects, aged between 18 and 64 years, a total of 6,510 face-to-face interviews (response rate 81.7\%) were conducted, and all subjects completed the Korean version of the Composite International Diagnostic Interview 2.1 (K-CIDI 2.1). ${ }^{14}$

The institutional review board of the Seoul National University College of Medicine approved this study. Each subject was fully informed on study aims and methods before interview completion. Informed consent was obtained prior to participation.

\section{Measures}

The Korean version of the Composite International Diagnostic Interview 2.1 (K-CIDI 2.1) was administered to each subject by trained lay interviewers. The $\mathrm{CIDI}^{15}$ is a fully structured diagnostic interview designed to determine psychiatric diagnoses using DSM-IV definitions. The K-CIDI was validated by Cho et al. ${ }^{16}$ according to WHO guidelines. Lifetime alcohol dependence was diagnosed if a subject has ever fulfilled the diagnostic criteria of alcohol dependence within the same time period. A separate estimate was made of whether those criteria had also been fulfilled within the past 12 months. If they had not, and lifetime alcohol dependence was not diagnosed, the subject was determined to be in remission from alcohol dependence. Comorbidity was defined as having suffered from more than one DSM-IV disorders assessed in the KECA study within the previous 12 months.

A number of socio-demographic variables were obtained through questions in separate sections of the K-CIDI. Age-at interview was categorized into four groups ( $\leq 34$ years, $35-44$ years, $45-54$ years, and $\geq 55$ years). Marital status was categorized into 'Living with partner' and 'Not-living with partner' (partner including not only family but also live-in partner).

Employment status was classified according to whether the 
subject was currently 1) full- time employed, 2) part-time employed, 3) student or homemaker, or 4) unemployed. Education level was assumed to be orderly and categorized into 1) below a junior high school graduate ( $0-9$ years), 2) senior high school (10-12 years), and 3 ) university or more (13 years or more).

\section{Interviewer training}

A total of 78 interviewers with experience in psychiatric epidemiologic surveys and familiar with their area of study were recruited from each catchment area. All interviewers received a 5-day training session that included didactic sessions concerning general interview skills and the interview instruments, mock interviews, and role-playing exercises using standard protocols and training materials developed by the World Health Organization.

\section{Statistical analysis}

Demographic and clinical variables putatively associated with remission from alcohol dependence were examined by basic bivariate analyses, applying the t-test and the chi-squaretest. Values of $p<0.05$ were considered statistically significant. The odds ratios (ORs) and $95 \%$ confidence intervals (CIs) of sociodemographic and clinical variables that differentiate active and remitted alcohol dependence were derived from logistic regression analyses, adjusting for age and sex. SPSS (version 18.0) statistical packages were used for the analyses.

\section{RESULTS}

The lifetime prevalence rate of alcohol dependence was 7.0\% (458/6510). Table 1 and 2 show the sociodemographic and clinical factors of whole participants and subjects with currently active or remitted alcohol dependence, respectively. Table 3 displays the results of logistic regression analysis. When adjusted for age and gender, $3.2 \%$ of the subjects were diagnosed with alcohol dependence in the previous 12 months, and $3.8 \%$ were found to be in remission (defined as having no symptom of alcohol dependence for 12 months or longer at the time of the interview).

No differences between age and gender were observed between the two groups. The actively alcohol dependent subjects were more prevalent in the 35-44 years group than the 5564 years group (adjusted OR 2.74, 95\% CI 1.25-5.60). Active alcohol dependence was more common among subjects not living with a partner compared to subjects living with a partner and less common in part-time employed subjects compared to full-time employed subjects. As shown in Table 3, when adjusted for age and gender in a logistic regression model, these associations remained significant (adjusted OR
Table 1. Sociodemographic and clinical factors of general population

\begin{tabular}{|c|c|}
\hline Variable & $\begin{array}{c}\text { All }(\mathrm{N}=6510) \\
(\%)\end{array}$ \\
\hline \multicolumn{2}{|l|}{ Sociodemographic factors } \\
\hline Male sex & 50.4 \\
\hline Mean age (years) & 36.1 \\
\hline \multicolumn{2}{|l|}{ Age group } \\
\hline$\leq 34$ years & 39.8 \\
\hline $35-44$ years & 25.9 \\
\hline $45-54$ years & 21.2 \\
\hline$\geq 55$ years & 13.1 \\
\hline \multicolumn{2}{|l|}{ Marital status } \\
\hline Living with partner & 67.4 \\
\hline NLWP & 32.6 \\
\hline \multicolumn{2}{|l|}{ Employment status } \\
\hline Employed (full time) & 54.8 \\
\hline Employed (part time) & 5.8 \\
\hline Student or homemaker & 33.4 \\
\hline Unemployed & 5.9 \\
\hline \multicolumn{2}{|l|}{ Educational level } \\
\hline $0-9$ years & 18.1 \\
\hline $10-12$ years & 35.8 \\
\hline 13-years & 46.0 \\
\hline \multicolumn{2}{|l|}{ Clinical factors } \\
\hline Major depressive disorder & 2.5 \\
\hline Dysthymia & 0.3 \\
\hline Any anxiety disorders & 5.3 \\
\hline Agoraphobia & 0.2 \\
\hline PTSD & 0.7 \\
\hline Social phobia & 0.4 \\
\hline GAD & 0.8 \\
\hline Nicotine use & 6.0 \\
\hline Nicotine dependence & 5.1 \\
\hline $\begin{array}{l}\text { Any DSM-IV psychiatric disorders } \\
\text { (except nicotine and alcohol use disorder) }\end{array}$ & 8.5 \\
\hline
\end{tabular}

NLWP: not living with partner, PTSD: post-traumatic stress disorder, GAD: generalized anxiety disorder, DSM-IV: Diagnostic and Statistical Manual of Mental Disorders, fourth edition

1.69, CI 1.09-2.62 and adjusted OR 0.25 CI 0.09-0.75, respectively). In bivariate analysis, no differences of educational levels were observed between active alcohol dependent and remitted subjects. But, after adjusting for age and sex in the logistic regression model, subjects with lower level of education were more frequently in an active alcohol dependent state relative to subjects with higher levels of education (adjusted OR 2.09, 95\% CI 1.09-3.40). 
The one-year prevalence rates of any DSM-IV psychiatric disorder (except alcohol and nicotine use disorder) were higher in active alcohol dependent subjects than in the remitted ones (24.8 vs. $15.5, \mathrm{p}=0.013$ ), with an OR value of 1.96 . Dysthymia, any anxiety disorder, agoraphobia, PTSD, nicotine use, and nicotine dependence were significantly more common in the actively alcohol dependent subjects than in the remitted ones. When adjusted for age and sex in a logistic regression model, any anxiety disorder, PTSD, nicotine use and nicotine dependence were significantly associated with active alcohol dependence, with OR values from 1.64 to 8.87. Dys- thymia and agoraphobia were not anlayzed in the logistic regression model due to low sample size. There was no significant difference in the mean age of alcohol dependence onset between active and remitted subjects (24.3 years vs. 24.1 years, $\mathrm{t}=-0.23$, n.s., data not shown in Table).

\section{DISCUSSION}

This study is a general population-based study to examine factors associated with remission from alcohol dependence in South Korea. In this study, the rate of 1-year full remission

Table 2. Sociodemographic and clinical factors among subjects with currently active and remitted alcohol dependence

\begin{tabular}{|c|c|c|c|}
\hline Variable & $\begin{array}{l}\text { Active alcohol dependence } \\
\qquad(\mathrm{N}=207,3.2 \%)(\%)\end{array}$ & $\begin{array}{l}\text { Remitted alcohol dependence } \\
\qquad(\mathrm{N}=251,3.9 \%)(\%)\end{array}$ & $\begin{array}{l}\text { Act vs. remitted } \\
\mathrm{p} \\
\end{array}$ \\
\hline \multicolumn{4}{|l|}{ Sociodemographic factors } \\
\hline Male sex & 74.3 & 73.3 & 0.816 \\
\hline Mean age (years) & 35.2 & 36.8 & 0.142 \\
\hline \multicolumn{4}{|l|}{ Age group } \\
\hline$\leq 34$ years & 49.8 & 51.4 & \\
\hline $35-44$ years & 27.5 & 18.3 & \\
\hline $45-54$ years & 16.9 & 19.5 & \\
\hline$\geq 55$ years & 5.8 & 10.8 & 0.045 \\
\hline \multicolumn{4}{|l|}{ Marital status } \\
\hline Living with partner & 43.6 & 53.6 & \\
\hline Not living with partner & 56.4 & 46.4 & 0.034 \\
\hline \multicolumn{4}{|l|}{ Employment status } \\
\hline Employed (full time) & 57.6 & 57.8 & \\
\hline Employed (part time) & 2.3 & 10.2 & \\
\hline Student or homemaker & 29.1 & 23.6 & \\
\hline Unemployed & 11.0 & 8.4 & 0.013 \\
\hline \multicolumn{4}{|l|}{ Educational level } \\
\hline $0-9$ years & 15.9 & 13.1 & \\
\hline $10-12$ years & 34.8 & 31.5 & \\
\hline 13-years & 49.3 & 55.4 & 0.408 \\
\hline \multicolumn{4}{|l|}{ Clinical factors } \\
\hline Major depressive disorder & 6.8 & 6.0 & 0.731 \\
\hline Dysthymia* & 1.9 & 0.0 & 0.041 \\
\hline Any anxiety disorders & 17.9 & 8.8 & 0.004 \\
\hline Agoraphobia* & 2.9 & 0.0 & 0.008 \\
\hline PTSD* & 3.9 & 0.4 & 0.013 \\
\hline Social phobia* & 1.9 & 0.8 & 0.416 \\
\hline $\mathrm{GAD}^{*}$ & 5.3 & 3.2 & 0.122 \\
\hline Nicotine use & 27.5 & 18.7 & 0.025 \\
\hline Nicotine dependence & 24.6 & 16.7 & 0.036 \\
\hline $\begin{array}{l}\text { Any DSM-IV psychiatric disorders } \\
\text { (except nicotine and alcohol use disorder) }\end{array}$ & 24.8 & 15.5 & 0.013 \\
\hline
\end{tabular}

*Fisher exact test. PTSD: post-traumatic stress disorder, GAD: generalized anxiety disorder, DSM-IV: Diagnostic and Statistical Manual of Mental Disorders, fourth edition 
Table 3. Age- and sex-adjusted odds ratios for different characteristics predicting active alcohol dependence (AD)

\begin{tabular}{|c|c|}
\hline Variable & $\begin{array}{l}\text { Age- and sex-adj. } \\
\text { OR and } 95 \% \mathrm{CI} \text { for } \\
\text { active vs. remitted } \\
\mathrm{AD}(\mathrm{N}=458)\end{array}$ \\
\hline \multicolumn{2}{|l|}{ Age group } \\
\hline$\leq 34$ years & $1.77(0.85-3.67)$ \\
\hline $35-44$ years & $2.74(1.25-5.60)^{*}$ \\
\hline $45-54$ years & $1.55(0.69-3.48)$ \\
\hline$\geq 55$ years & 1 (reference) \\
\hline \multicolumn{2}{|l|}{ Marital status } \\
\hline Living with partner & 1 (reference) \\
\hline Not living with partner & $1.69(1.09-2.62)^{*}$ \\
\hline \multicolumn{2}{|l|}{ Employment status } \\
\hline Employed (full time) & 1 (reference) \\
\hline Employed (part time) & $0.25(0.09-0.75)^{*}$ \\
\hline Student or homemaker & $1.41(0.83-2.38)$ \\
\hline Unemployed & $1.54(0.76-3.13)$ \\
\hline \multicolumn{2}{|l|}{ Educational level } \\
\hline 0-9 years & $2.09(1.09-3.40)^{*}$ \\
\hline $10-12$ years & $1.31(0.84-2.04)$ \\
\hline 13-years & 1 (reference) \\
\hline \multicolumn{2}{|l|}{ Clinical factors ${ }^{\dagger}$} \\
\hline Major depressive disorder & $1.19(0.56-2.56)$ \\
\hline \multicolumn{2}{|l|}{ Dysthymia $^{\ddagger}$} \\
\hline Any anxiety disorders & $2.41(1.35-4.30)^{*}$ \\
\hline \multicolumn{2}{|l|}{ Agoraphobia ${ }^{\ddagger}$} \\
\hline PTSD & $8.87(1.23-63.95)^{*}$ \\
\hline Social phobia & $3.26(0.58-18.46)$ \\
\hline GAD & $3.44(0.80-14.71)$ \\
\hline Nicotine use & $1.71(1.08-2.70)^{*}$ \\
\hline Nicotine dependence & $1.64(1.02-2.63)^{*}$ \\
\hline $\begin{array}{l}\text { Any DSM-IV psychiatric disorders } \\
\text { (except nicotine and alcohol } \\
\text { use disorder) }\end{array}$ & $1.96(1.19-3.11)^{*}$ \\
\hline
\end{tabular}

${ }^{*}$ factor not present, ${ }^{\dagger}$ put as empty since the sample size were too small to be estimated, \#statistically significant findings, $\mathrm{p}<0.05$. PTSD: post-traumatic stress disorder, GAD: generalized anxiety disorder, DSM-IV: Diagnostic and Statistical Manual of Mental Disorders, fourth edition

from DSM-IV alcohol dependence was 55\%. This rate is comparable to the 1-year full remission rate from DSM-IV alcohol dependence in the U.S. (48\%), ${ }^{17}$ the 1-year partial remission rate in a German representative population sample $(64 \%))^{18}$ and the 1-year full remission rate from alcohol abuse and dependence in Ontario, Canada (53\%). ${ }^{19}$

Previous studies in Korea indicated that the male gender is a consistent risk factor for alcohol use disorder. ${ }^{3}$ In this study, whereas one-year prevalence of alcohol dependence was much higher in males than in females, there was no gender difference in remission from alcohol dependence. Our finding is not consistent with that of Dawson and colleagues ${ }^{17}$ that abstinent and non-abstinent recovery in the general U.S population are associated with the female gender. This discrepancy could be explained by the rapidly increasing prevalence of alcohol use disorder among South Korean females. In fact, the male to female ratio of alcohol use disorder was extremely high in 1984 (16.3 in Seoul, 27.3 in rural areas) ${ }^{20,21}$ but dropped to 4.4 in 2001 and 3.7 in $2006 .{ }^{4}$ As a result of increased social status and rights of women in Korea and a decline in societal pressures to act in accordance with the prescribed traditional gender roles, women now can choose to drink alcohol more freely, making it difficult for them to reach or to maintain the remitted state. Therefore, the importance of alcohol-related problems in women should not be underestimated when planning for alcohol dependence recovery programs in the future.

The remission rate from alcohol dependence has been reported to increase with age, ${ }^{17}$ but this trend was not observed in our study sample. Accordingly, subjects in the 35- to 44 yearold age group were more likely to be in the active alcohol dependent state compared to the oldest age group (55- to 64 year-old). This finding might relate to the fact that 35 - to 44 year-old group is the most economically active population..$^{22} \mathrm{In}$ Korea, social and business binge drinking is popular and generally socially accepted., ${ }^{3,1621}$ Moreover, Koreans have a unique drinking culture with powerful social pressures for large alcohol consumptions during dinner meetings. In addition, Koreass corporate cultural tradition involves drinking for the purpose of fostering solidarity within a group and for relaxation. ${ }^{23}$ According to the Korean National Statistical Office, $43.6 \%$ of drinkers replied that abstaining from alcohol is difficult due to social necessity, especially in the workplace. ${ }^{24}$ Future research should examine whether the negative association to remission for alcohol dependence in the 35- to 44 year-old group is a work-related issue.

In terms of educational level, subjects who completed 0-9 years education were at increased risk of active alcohol dependence compared to subjects who completed above 13 years education. This may be explained by the statistics that those with lower education are not only in the Agri-fishery industry but also have simple labor jobs in Korea. ${ }^{25}$ People in these lines of work have been reported to drink more frequently, according to Korean National Statistical Office. ${ }^{26}$ This might contribute to the increased risk of active alcohol dependence in the lower educational group. However, the relationship between remission from alcohol dependence and educational level still remains controversial. Unlike our finding, a prior 
study in the U.S. reported that college education decreased the likelihood of abstinence. ${ }^{17}$

We found that people not living with a partner were more common in the active alcohol dependence group than in the remission group. This finding is consistent with previous Western studies, ${ }^{7,17}$ suggesting importance of a social support, either family or others, in promoting remission.

Interestingly, we found that major depressive disorders were not associated with remission for alcohol dependence but that individuals with any anxiety disorder and dysthymia had a reduced likelihood of achieving remission for alcohol dependence. Previous studies on the impact of major depressive disorder comorbidities in subjects treated for substance use disorder have generated inconsistent results. While some studies found that the likelihood of remission is lower for individuals also diagnosed with a major depressive disorder, ${ }^{27-29}$ other revealed no differences between comorbid and noncomorbid subjects. ${ }^{30,31}$ This may be explained by the generally episodic and remitting nature of major depressive disorders. In contrast, anxiety disorders and dysthymia have a long-term and prevailing nature. We may hypothesize that self-medication against the disturbing symptoms of anxiety disorder or dysthymia may be a source of continuous alcohol use among the actively dependent. This finding fits with "tension-reduction" hypothesis of alcohol dependence, a major premise is that the anxiolytic effects of alcohol reinforce drinking behavior and can lead to pathologic drinking. ${ }^{32}$

Although depressive symptoms caused by alcohol were not assessed in this study, prior studies have shown that substanceinduced and abstinence-related depression are risk factors for alcohol relapse $e^{28,33,34}$ and recovery from depression increases the chance of recovery from alcoholism, reducing relapse risk. ${ }^{35}$ Longitudinal studies deal with course and interactions between independent or substance-induced mood disorders with remission for alcohol dependence need to definitely address this issue.

Of particular note is our finding that comorbidity of posttraumatic stress disorder (PTSD) was largely associated with maintenance of active alcohol dependence. Previous studies have shown that men and women with PTSD more likely to have alcohol dependence compared with the general population $^{2,36,37}$ and comorbidity between PTSD and alcohol dependence may be attributed in part to overlapping genetic influence. ${ }^{38}$ Improvements in PTSD had a greater impact on improvements in comorbid PTSD and alcohol dependence. ${ }^{39}$

Nicotine use and dependence were also more common in active alcohol dependent subjects than the remitted subjects. The prevalence of nicotine dependence among people with alcohol dependence was over two times higher (45\%) than in the general population according to an epidemiological study in the U.S. ${ }^{40}$ The prevalence of smoking in the clinical population of alcoholics is estimated to be as high as $80 \%{ }^{41} \mathrm{Hu}$ man studies suggest that nicotine intake primes alcohol consumption $^{42}$ and that alcohol intake acutely increases smoking behavior and nicotine reward. ${ }^{43}$ Animal studies suggest that such "cross sensitivity" has a genetic component. ${ }^{44}$ In addition, the preponderance of studies of concurrent smoking and alcohol treatment indicate that concurrent treatment does not jeopardize abstinence from alcohol..$^{45}$ Taken together, treatment of nicotine dependence in smokers with comorbid alcohol dependence is important to enhance recovery from alcohol dependence.

There are several limitations to note. First, since this study was a cross-sectional study, we could not examine the causal relations between active alcohol dependence and other psychiatric disorders. In addition, cross-sectional data do not necessarily reflect the course of recovery across time for any given individual. Therefore, longitudinal alcohol epidemiologic survey with a larger sample size would be necessary to examine the natural history of alcohol dependence over time at the individual level. Second, since data collection was restricted to a non-institutionalized population, severely impaired subjects might be under-represented in the sample. According to Korean National Health Insurance database (www.nhic.or.kr), the number of patients admitted to hospital for alcohol problem (F10) was estimated about 21,000 in 2005. Third, recall bias might have affected the prevalence rates of psychiatric disorders, especially in the elderly subjects, due to the retrospective nature of the data used. Forth, despite a relatively good response rate $(81.7 \%)$ in the final CIDI interview, we cannot exclude the possibility that the non-respondent population may have included subjects with poorer psychosocial functioning and/or more severe problems with alcohol. Thus, actual characteristics of the alcohol-dependent subjects among the non-respondents could not be explored. Finally, due to the retrospective nature of the present study, mortality could not be considered as a critical issue in the course of alcohol use disorders.

Despite these limitations, this report represents an important first step in identifying factors associated with remission from alcohol dependence in Korea. The prevalence of alcohol dependence in Korea is still higher than in other countries in Asia and comparable to western countries. We suggest that our society needs to increase a public awareness to encourage the treatment of alcohol dependence. Such actions may help to lessen the suffering from alcohol dependence on individuals, and reduce the economic burden on society. Our findings, if corroborated by further studies, will help identify highrisk individuals and potentially improve the remission of patients with alcohol dependence. 


\section{Acknowledgments}

The authors wish to express their gratitude to 12 local investigators, 79 interviewers, and the Korean Ministry of Health \& Welfare for their support and cooperation.

\section{REFERENCES}

1. Kessler RC, McGonagle KA, Zhao S, Nelson CB, Hughes M, Eshleman $\mathrm{S}$, et al. Lifetime and 12-month prevalence of DSM-III-R psychiatric disorders in the United States. Results from the National Comorbidity Survey. Arch Gen Psychiatry 1994;51:8-19.

2. Kessler RC, Crum RM, Warner LA, Nelson CB, Schulenberg J, Anthony JC. Lifetime co-occurrence of DSM-III-R alcohol abuse and dependence with other psychiatric disorders in the National Comorbidity Survey. Arch Gen Psychiatry 1997;54:313-321.

3. Hahm BJ, Cho MJ. Prevalence of alcohol use disorder in a South Korean community: changes in the pattern of prevalence over the past 15 years. Soc Psychiatry Psychiatr Epidemiol 2005;40:114-119.

4. Cho MJ, Chang SM, Hahm BJ, Chung IW, Bae A, Lee YM, et al. Prevalence and correlates of major mental disorders among Korean adults: A 2006 National Epidemiologic Survey. J Korean Neuropsychiatr Assoc 2009;48:143-152.

5. Lee HK, Chou SP, Cho MJ, Park JI, Dawson DA, Grant BF. The prevalence and correlates of alcohol use disorders in the United States and Korea--a cross-national comparative study. Alcohol 2010;44:297-306.

6. Dawson DA. Symptoms and characteristics of individuals with different types of recovery from DSM-IV alcohol dependence. J Subst Abuse 1998;10:127-142.

7. McAweeney MJ, Zucker RA, Fitzgerald HE, Puttler LI, Wong MM. Individual and partner predictors of recovery from alcohol-use disorder over a nine-year interval: findings from a community sample of alcoholic married men. J Stud Alcohol 2005;66:220-228.

8. Moos RH, Moos BS. Protective resources and long-term recovery from alcohol use disorders. Drug Alcohol Depend 2007;86:46-54.

9. Cho MJ, Hahm BJ, Suh T, Suh GH, Cho SJ, Lee CK. Comorbid mental disorders among the patients with alcohol abuse and dependence in Korea. J Korean Med Sci 2002;17:236-241.

10. Charney DA, Palacios-Boix J, Negrete JC, Dobkin PL, Gill KJ. Association between concurrent depression and anxiety and six-month outcome of addiction treatment. Psychiatr Serv 2005;56:927-933.

11. Grant BF. Comorbidity between DSM-IV drug use disorders and major depression: results of a national survey of adults. J Subst Abuse 1995; 7:481-497.

12. Kushner MG, Abrams K, Thuras P, Hanson KL, Brekke M, Sletten S. Follow-up study of anxiety disorder and alcohol dependence in comorbid alcoholism treatment patients. Alcohol Clin Exp Res 2005;29: 1432-1443.

13. Evren C, Sar V, Dalbudak E, Oncu F, Cakmak D. Social anxiety and dissociation among male patients with alcohol dependency. Psychiatry Res 2009;165:273-280.

14. Cho MJ, Hahm BJ, Suh DW, Hong JP, Bae JN, Kim JK, et al. Development of a Korean version of the Composite International Diagnostic Interview (K-CIDI). J Korean Neuropsychiatr Assoc 2002;41:123-137.

15. World Health Organization. Composite International Diagnostic Interview (CIDI), Version 1.0. Geneva: World Health Organization; 1990.

16. Cho MJ, Kim JK, Jeon HJ, Suh T, Chung IW, Hong JP, et al. Lifetime and 12-month prevalence of DSM-IV psychiatric disorders among Korean adults. J Nerv Ment Dis 2007;195:203-210.

17. Dawson DA, Grant BF, Stinson FS, Chou PS, Huang B, Ruan WJ. Recovery from DSM-IV alcohol dependence: United States, 2001-2002. Addiction 2005;100:281-292.

18. Bischof G, Rumpf HJ, Meyer C, Hapke U, John U. Influence of psychiatric comorbidity in alcohol-dependent subjects in a representative population survey on treatment utilization and natural recovery. Addiction 2005;100:405-413.
19. Cunningham JA, Lin E, Ross HE, Walsh GW. Factors associated with untreated remissions from alcohol abuse or dependence. Addict Behav 2000;25:317-321.

20. Lee CK, Kwak YS, Yamamoto J, Rhee H, Kim YS, Han JH, et al. Psychiatric epidemiology in Korea. Part I: Gender and age differences in Seoul. J Nerv Ment Dis 1990;178:242-246.

21. Lee CK, Kwak YS, Yamamoto J, Rhee H, Kim YS, Han JH, et al. Psychiatric epidemiology in Korea. Part II: Urban and rural differences. J Nerv Ment Dis 1990;178:247-252.

22. Korean National Statistical Office. Economically Active Population Survey. Daejeon: Korean National Statistical Office; 2011.

23. Kweon GY. Factors influencing drinking of employees: focus on the white collar employees. Korean J Soc Welfare 2005;57:93-118.

24. Korean National Statistical Office. National Family Health Survey. Daejeon: Korean National Statistical Office; 2008.

25. Korean National Statistical Office. Educational attainment by job group. Daejeon: Korean National Statistical Office; 2006.

26. Korean National Statistical Office. Frequency of drinking by job group. Daejeon: Korean National Statistical Office; 2006.

27. Glenn SW, Parsons OA. Prediction of resumption of drinking in posttreatment alcoholics. Int J Addict 1991;26:237-254.

28. Hasin D, Liu X, Nunes E, McCloud S, Samet S, Endicott J. Effects of major depression on remission and relapse of substance dependence. Arch Gen Psychiatry 2002;59:375-380.

29. Rounsaville BJ, Dolinsky ZS, Babor TF, Meyer RE. Psychopathology as a predictor of treatment outcome in alcoholics. Arch Gen Psychiatry 1987;44:505-513.

30. Davidson KM, Blackburn IM. Co-morbid depression and drinking outcome in those with alcohol dependence. Alcohol Alcohol 1998;33: 482-487.

31. Kranzler HR, Del Boca FK, Rounsaville BJ. Comorbid psychiatric diagnosis predicts three-year outcomes in alcoholics: a posttreatment natural history study. J Stud Alcohol 1996;57:619-626.

32. Cappell H, Herman CP. Alcohol and tension reduction. A review. Q J Stud Alcohol 1972;33:33-64.

33. Curran GM, Booth BM. Longitudinal changes in predictor profiles of abstinence from alcohol use among male veterans. Alcohol Clin Exp Res 1999;23:141-143.

34. Greenfield SF, Weiss RD, Muenz LR, Vagge LM, Kelly JF, Bello LR, et al. The effect of depression on return to drinking: a prospective study. Arch Gen Psychiatry 1998;55:259-265.

35. Hasin DS, Tsai WY, Endicott J, Mueller TI, Coryell W, Keller M. Fiveyear course of major depression: effects of comorbid alcoholism. J Affect Disord 1996;41:63-70.

36. Perkonigg A, Kessler RC, Storz S, Wittchen HU. Traumatic events and post-traumatic stress disorder in the community: prevalence, risk factors and comorbidity. Acta Psychiatr Scand 2000;101:46-59.

37. Danielson CK, Amstadter AB, Dangelmaier RE, Resnick HS, Saunders BE, Kilpatrick DG. Trauma-related risk factors for substance abuse among male versus female young adults. Addict Behav 2009;34:395-399.

38. Sartor CE, McCutcheon VV, Pommer NE, Nelson EC, Grant JD, Duncan $\mathrm{AE}$, et al. Common genetic and environmental contributions to posttraumatic stress disorder and alcohol dependence in young women. Psychol Med 2011;41:1497-1505.

39. Back SE, Brady KT, Sonne SC, Verduin ML. Symptom improvement in co-occurring PTSD and alcohol dependence. J Nerv Ment Dis 2006; 194:690-696.

40. Grant BF, Hasin DS, Chou SP, Stinson FS, Dawson DA. Nicotine dependence and psychiatric disorders in the United States: results from the national epidemiologic survey on alcohol and related conditions. Arch Gen Psychiatry 2004;61:1107-1115.

41. Kalman D, Morissette SB, George TP. Co-morbidity of smoking in patients with psychiatric and substance use disorders. Am J Addict 2005; 14:106-123.

42. Barrett SP, Tichauer M, Leyton M, Pihl RO. Nicotine increase alcohol 
self-administration in non-dependent male smokers. Drug Alcohol Depend 2006;81:197-204.

43. McKee SA, Krishnan-Sarin S, Shi J, Mase T, O’Malley SS. Modeling the effect of alcohol on smoking lapse behavior. Psychopharmacology (Berl) 2006;189:201-210.

44. Balogh SA, Owens JC, Butt CM, Wehner JM, Collins AC. Animal mod- els as a tool for studying mechanisms of co-abuse of alcohol and tobacco. Alcohol Clin Exp Res 2002;26:1911-1914.

45. Prochaska JJ, Delucchi K, Hall SM. A meta-analysis of smoking cessation interventions with individuals in substance abuse treatment or recovery. J Consult Clin Psychol 2004;72:1144-1156. 